University of Nebraska - Lincoln

DigitalCommons@University of Nebraska - Lincoln

\title{
Experimental assessment of predation risk for juvenile green sturgeon, Acipenser medirostris, by two predatory fishes
}

S. Baird

A. E. Steel

D. E. Cocherell

Jamilynn B. Poletto

University of Nebraska - Lincoln, jpoletto2@unl.edu

R. Follenfant

See next page for additional authors

Follow this and additional works at: https://digitalcommons.unl.edu/natrespapers

Part of the Natural Resources and Conservation Commons, Natural Resources Management and Policy Commons, and the Other Environmental Sciences Commons

Baird, S.; Steel, A. E.; Cocherell, D. E.; Poletto, Jamilynn B.; Follenfant, R.; and Fangue, N. A., "Experimental assessment of predation risk for juvenile green sturgeon, Acipenser medirostris, by two predatory fishes" (2019). Papers in Natural Resources. 1071.

https://digitalcommons.unl.edu/natrespapers/1071

This Article is brought to you for free and open access by the Natural Resources, School of at DigitalCommons@University of Nebraska - Lincoln. It has been accepted for inclusion in Papers in Natural Resources by an authorized administrator of DigitalCommons@University of Nebraska - Lincoln. 
Authors

S. Baird, A. E. Steel, D. E. Cocherell, Jamilynn B. Poletto, R. Follenfant, and N. A. Fangue

This article is available at DigitalCommons@University of Nebraska - Lincoln: https://digitalcommons.unl.edu/ natrespapers/1071 


\title{
Experimental assessment of predation risk for juvenile green sturgeon, Acipenser medirostris, by two predatory fishes
}

\author{
Sarah E. Baird (i) | Anna E. Steel (D) | Dennis E. Cocherell | Jamilynn B. Poletto | \\ Rhiannon Follenfant | Nann A. Fangue
}

Department of Wildlife, Fish and Conservation Biology, University of California Davis, Davis, California

\section{Correspondence}

Nann A. Fangue, Department of Wildlife, Fish and Conservation Biology, University of California Davis, One Shields Avenue, Davis, CA 95616.

Email: nafangue@ucdavis.edu

\section{Present address}

Jamilynn B. Poletto, School of Natural Resources, University of Nebraska-Lincoln, Lincoln, NE

\section{Funding information}

California Department of Water Resources; UC Davis Agricultural Experiment Station, Grant/Award Number: 2098-H

\begin{abstract}
Predation is a common cause of early life stage mortality in fishes, with reduced risk as individuals grow and become too large to be consumed by gape-limited predatory fishes. Large-bodied species, such as sturgeon, may reach this size-refuge within the first year. However, there is limited understanding of what this size threshold is despite the value of this information for conservation management. We conducted laboratory-based predation experiments on juvenile green sturgeon, Acipenser medirostris, to estimate vulnerability to predation during outmigration from their natal reaches in California to the Pacific Ocean. Two highly abundant and non-native predatory fish species (largemouth bass, Micropterus salmoides, and striped bass, Morone saxatilis) were captured in the wild to be tested with developing juvenile green sturgeon from the UC Davis Green Sturgeon Broodstock Program. Experimental tanks, each containing five predators, received thirty prey for 24-hr exposures. Between sturgeon prey trials, predators were exposed to alternative prey species to confirm predators were exhibiting normal feeding behaviors. In addition to green sturgeon mortality data, trials were video recorded and predatory behaviors were quantified. Overall, these predator species displayed much lower rates of predation on juvenile green sturgeon than alternate prey. Predation decreased with green sturgeon size, and predation risk diminished to zero once sturgeon reached a length threshold of roughly $20-22 \mathrm{~cm}$ total length, or between $38 \%$ and $58 \%$ of predator total length. Behavioral analyses showed low motivation to feed on green sturgeon, with both predators attempting predation less frequently as sturgeon grew. Results of this study imply that optimizing growth rates for larval and juvenile sturgeon would shorten the time in which they are vulnerable to predation. Future experiments should assess predation risk of juvenile green sturgeon by additional predator species common to the Sacramento-San Joaquin watershed.
\end{abstract}

\section{KEYWORDS}

green sturgeon, largemouth bass, predation, striped bass

\section{1 | INTRODUCTION}

Sturgeon populations across the globe have been experiencing drastic population declines. Consequently, sturgeon are the most threatened group of animals on the IUCN Red List of Threatened Species, with $63 \%$ of the species listed as Critically Endangered and $85 \%$ at risk of extinction (IUCN 2019). Sturgeon are large-bodied and long-lived, with unique reproductive strategies such as late maturation and infrequent 
spawning that can result in low recruitment (Birstein, 1993). In addition, poor survival of the egg to sub-adult stages is a strong contributor to recruitment failure (Houde, 1987). Therefore, to effectively manage the recovery of imperiled sturgeon populations, it is imperative to quantify the sources of mortality in early life stages, especially those that are poorly understood, such as predation pressure.

The green sturgeon (Acipenser medirostris) is one of two sturgeon species endemic to the Pacific coast of North America and is one of the most anadromous of all sturgeon species (Allen \& Cech, 2007). Sub-adults and adults in the ocean are widely distributed from the Bering Sea, Alaska to Baja California, Mexico, yet green sturgeon spawn in relatively small and discrete habitats. Genetic evidence suggests two distinct populations of green sturgeon (Israel, Cordes, Blumberg, \& May, 2004), including a southern population that spawns only within the Sacramento-San Joaquin basin. The U.S. Endangered Species Act recognizes the Northern and Southern Distinct Population Segments (nDPS and sDPS, respectively) and lists the sDPS as threatened (NMFS 2006).

Over the past several decades, juvenile green sturgeon abundance has decreased (Adams et al., 2007) but the underlying mechanisms responsible for reduced abundances remain elusive. Potential factors contributing to population declines of green sturgeon include altered temperature and flow regimes, altered prey base, competition and predation by native and non-native fishes (NMFS 2018). As juvenile green sturgeon migrate from their natal reaches of the upper watersheds to the estuaries and bays they encounter a multitude of obstacles, including many predatory fishes. Anadromous populations of many fishes are sensitive to early life stage predation prior to and during their juvenile outmigration, suggesting these same pressures may be contributing to recruitment failure in green sturgeon (Coutant, 2004; Houde, 1987; Parsley, Anders, Miller, Beckman, \& McCabe, 2002).

Predation on larval and juvenile green sturgeon has been formally identified by the National Marine Fisheries Service (NMFS) as a medium to high risk on survival rates, yet data for green sturgeon remains insufficient to draw definitive conclusions (NMFS 2018). Dynamics between predators and prey are often size-structured (Persson, Andersson, Wahlstrom, \& Eklov, 1996, Gaeta et al. 2018), and parsing out these relationships is valuable for species conservation efforts (Houde, 1987). A study on juvenile white sturgeon (A. transmontanus), a sympatric sturgeon species, found significant predation on juveniles by common fish species in the Columbia River basin, including channel catfish (Ictalurus punctatus), northern pikeminnow (Ptychocheilus oregonensis), prickly scuplin (Cottus asper), and walleye (Sander vitreus), and determined predation rates to be dependent on prey size (Gadomski \& Parsley, 2005). Similarly, predation may also be a source of juvenile green sturgeon mortality in the Sacramento-San Joaquin Delta, a highly altered system with thousands of man-made structures known to aggregate large numbers of predatory fish species (Davis, Schultz, \& Vokoun, 2012; Grossman, 2016). This novel environment, through which juvenile green must migrate, may therefore increase the opportunity for predation.

Here, we quantified size-based predation risk of juvenile green sturgeon in laboratory experiments, using two common predators of the Sacramento-San Joaquin Delta, largemouth bass (Micropterus salmoides) and striped bass (Morone saxatillis). We selected these two predatory species due to their generalist tendencies, wide distributions, and high abundances in the sDPS natal river systems (Kano, 1990). Additionally, both of these predator species are non-native. Research on predator-prey dynamics with species not sharing an evolutionary history suggests that prey are often highly susceptible to predation by non-native predators (Kovalenko, Dibble, Agostinho, \& Pelicice, 2010; Sih et al., 2010). In part due to their non-native status and high abundance, these species are also targeted in various predatory removal programs within the distribution range of juvenile green sturgeon, such as the Clifton Court Forebay Predatory Fish Relocation Study performed by the California Department of Water Resources (CDWR, 2017). Furthermore, there is remarkably little data on predation rates of juvenile green sturgeon, and very little known about the life stages or sizes at which green sturgeon are most susceptible to predation. In most fish species, there is a size at which prey are afforded refuge from predation, primarily due to gape limitations of predators (Schael, Rudstam, \& Post, 1991). The size refuge to predation varies based upon the size and species of predator (Perrson et al. 1996), and it is unknown at what size juvenile green sturgeon reach a size refuge from predatory largemouth bass and striped bass.

To investigate green sturgeon mortality in the laboratory, our study focused on two principal questions: (a) Of these two common, non-native predators present in the Sacramento-San Joaquin Delta, which species predates upon juvenile green sturgeon most heavily, and (b) How do predation patterns change as green sturgeon grow? We hypothesized that there would not be significant differences in green sturgeon mortality between the two predatory species due to the highly overlapping generalist diets of both predators (Grossman, 2016). We also hypothesized that predation would peak when green sturgeon juveniles are small, and that predation would decrease to zero as green sturgeon grow. As green sturgeon develop, their protective scutes become larger and more dense, and the sturgeon's size will eventually surpass predator gape limitations.

\section{2 | MATERIALS AND METHODS}

\section{1 | Predator collection}

Largemouth bass, and potential black bass hybrids (Micropterus salmoides and M. punctulatus), were collected by CDWR via boat electroshocking (Smith-Root ${ }^{\circledR}$ Generator Powered Pulsator, 7.5 shore unit) in the Clifton Court Forebay (Contra Costa County, CA). Fish were obtained in May 2016, assessed for injury and illness, and size selected. Upon arrival at the University of California, Davis' J. Amorocho Hydraulics Lab (UCD JAHL), bass $(n=25)$ were sorted into two size classes, small (range: $30-42 \mathrm{~cm}$ total length, $\mathrm{TL}$ ) and large (range: $44-54 \mathrm{~cm} \mathrm{TL}$ ), and placed in $3 \mathrm{~m}$ diameter experimental tanks. Water depth was maintained at $64 \mathrm{~cm}$, and overall tank 
volumes were 1,224 gallons. Size classes were chosen based on catch data from CDWR indicating these were the dominant size ranges of black bass in the Clifton Court Forebay. Fish were acclimated to $18-19^{\circ} \mathrm{C}$ in partially recirculating well-water for over three weeks. Dissolved oxygen consistently measured $>8.00 \mathrm{mg} \mathrm{O} \mathrm{O}^{-1}$ with water currents less than $10 \mathrm{~cm} / \mathrm{s}$ in all tanks. There were four replicate tanks of five small largemouth bass (mean $T L=34.5 \mathrm{~cm}$, $S D=2.7$ ) and a single tank of five large largemouth bass (mean $\mathrm{TL}=46.0 \mathrm{~cm}, S D=3.4$ ), due to limited availability of the large size class of largemouth bass.

Striped bass were collected at the U.S. Bureau of Reclamation's Central Valley Project pumping facility (Contra Costa County, CA) in May 2017 using carbon dioxide as a temporary anesthetic to allow capture. Fish $(n=30)$ were obtained and transported to UCD JAHL, sorted into experimental tanks based on size, and held in conditions identical to those used for largemouth bass. Three replicate tanks of five small striped bass (mean $T L=40.6 \mathrm{~cm}, S D=4.0$ ) and three replicate tanks of five large striped bass (mean $T L=47.9 \mathrm{~cm}, S D=3.5$ ) were used during the experimental season. During the trials, there were 12 striped bass mortalities, two of which were replaced by additional striped bass. If predators were lost, trials were conducted with a minimum of four striped bass.

\section{2 | Green sturgeon broodstock and juvenile rearing}

UC Davis green sturgeon broodstock (i.e. spawning adults) were obtained from eggs collected and fertilized in the Klamath River with support of the Yurok Nation, and subsequently reared to reproductive maturation at UCD (Van Eenennaam, Linares-Casenave, \& Doroshov, 2012). Juvenile green sturgeon used for experiments in 2016 were progeny of one wild female and two males, one wild and one F1 from current broodstock. The wild male and female green sturgeon were captured on April 22, 2016 by Yurok Tribe fishers and transported to UCD JAHL via a transport tank equipped with oxygen. Juvenile green sturgeon used for experiments in 2017 were hatched from a spawn using one F1 female and three F1 males from existing UC Davis broodstock. Adult green sturgeon were induced to spawn in tanks following procedures detailed in Van Eenennaam et al. (2012), and eggs were collected every $2 \mathrm{hr}$ over a 24-hr period. Collected eggs were incubated and hatched out in upwelling jars maintained at $15.0 \pm 1.0^{\circ} \mathrm{C}$. Peak larval hatch occurred on May 2, 2016 and April 17, 2017 for 2016 and 2017 experiments, respectively. Each year, post hatch larvae were acclimated to $18^{\circ} \mathrm{C}$ well water and transported to $450 \mathrm{~L}$ circular tanks equipped with flow through, air-equilibrated water at the Center for Aquatic Biology and Aquaculture (UCD CABA). Larvae were transitioned to feed at roughly 15 days post hatch (dph) using brine shrimp (Artemia spp., hatched in laboratory) and a semi-moist sturgeon starter feed (Rangen, Inc.). Sturgeon from both years were fed $110 \%$ of optimal feed rate determined for white sturgeon (Verhille et al., 2016; Zheng, Deng, Riu, Moniello, \& Hung, 2015) over a 24-hr period using continuous belt feeders (PENTAIR, Part \#: BFS12A).

\section{3 | Alternate prey}

In order to confirm willingness of the predators to feed, trials using an alternate prey species were staggered between those assessing predation on experimental sturgeon. Alternate prey species were chosen based on typical feeding behavior of each predator species, and prey availability in each year. Prior to arrival at UCD JAHL, largemouth bass were fed live juvenile Chinook salmon (Onchorynchus tshawytscha) at the CDWR fish facility. Thus, rainbow trout (O. mykiss), which were hatched and reared at UCD CABA, were chosen as the alternate prey species in 2016 due to their similarity to Chinook salmon. During the course of the 2016 trials, rainbow trout size increased from mean mass of $5.4 \mathrm{~g}$ to 20.3 g. For 2017 striped bass experiments, fathead minnows (Pimephales promelas) were chosen due to their slow growth rates (relative to rainbow trout that quickly outgrew the gape limitation for largemouth bass) and fusiform shape. Fathead minnows (mean mass $=2.0 \mathrm{~g}$ ) were commercially purchased (I.F. Anderson Farms, Inc. Lonoke, AR) and were held at UCD CABA in a single $450 \mathrm{~L}$ circular tank at $18^{\circ} \mathrm{C}$ in flow-through air equilibrated well water (DO > $9.00 \mathrm{mg} \mathrm{O}_{2} \mathrm{~L}^{-1}$ ).

\section{4 | Experimental design}

Experimental tanks were located outdoors at UCD JAHL and trials were conducted in the summer months of both 2016 and 2017. Trials with largemouth bass were conducted in 2016, while trials with striped bass were conducted in 2017. All trial periods were video recorded using overhead cameras (two cameras per tank) for additional behavioral analysis. Each tank was $3 \mathrm{~m}$ in diameter and fit with a heat pump and recirculating system to maintain consistent temperatures throughout experiments. Mean tank temperatures during 2016 and 2017 trials were $19.3^{\circ} \mathrm{C}(S D=0.3)$ and $18.3^{\circ} \mathrm{C}(S D=0.3)$, respectively. The recirculating system was equipped with a low-head fluidized media reactor and ultraviolet lights to maintain water quality, with the equivalent volume of the system turning over every four hours. Spray bars (water inflows) were submerged below the water line so the water surface was not disturbed for video analysis. Shade cloth was attached to an overhead structure to decrease sun glare and minimize algae growth for optimal visibility.

Every three days a predation experiment was initiated, each lasting $24 \mathrm{hr}$. Predators were fasted $48 \mathrm{hr}$ prior to each experiment to avoid predator satiation during the experimental period. To begin an experiment, green sturgeon or alternate prey were transported from the UCD CABA facility to UCD JAHL in large insulated coolers equipped with aeration (ca. 3 min drive) in the morning between 0800 and 1100 . Thirty prey (or 6 prey per predator with any trials using fewer than five predators) were placed inside a 
single acclimation hoop within each experimental tank for 30 min to allow recovery from transport and handling stress. Acclimation hoops were constructed using two $76.2 \mathrm{~cm}$ diameter polypropylene rings, one weighted and one floated, wrapped with fine-mesh netting. This created an enclosed cylinder with one ring floating on the surface and one ring resting on the bottom of the tank. Design of these hoops allowed both benthic (green sturgeon) and pelagic (rainbow trout, fathead minnow) prey to acclimate at their preferred depth in the water column. Experiments where then initiated when acclimation hoops were removed from a tank, exposing prey to the predators. After $24 \mathrm{hr}$, remaining prey were netted from each experimental tank and weighed, measured and assessed for injuries sustained during experiments. To avoid unnecessary handling stress and air immersion, sturgeon used in trials were not weighed and measured prior to the trial. Instead, a subset of 10-20 sturgeon from the source tanks were measured to provide an estimate of sturgeon size in the event that few sturgeon prey remained after the predator-prey exposure period. Experiments in 2016 and 2017 ran from July to August and from May to August, respectively.

\section{3 | DATA ANALYSIS}

\section{1 | Green sturgeon mortality}

For largemouth bass predation trials, the mean size of juvenile green sturgeon ranged from $10.6 \mathrm{~cm}$ TL (SD = 1.3) at $63 \mathrm{dph}$ to $21.7 \mathrm{~cm} \mathrm{TL}$ $(S D=2.1)$ at $105 \mathrm{dph}$. For striped bass predation trials, the mean size of juvenile green sturgeon ranged from $5.4 \mathrm{~cm} T L(S D=0.6)$ at $42 \mathrm{dph}$ to $22.0 \mathrm{~cm}$ TL $(S D=1.8)$ at $114 \mathrm{dph}$. There were a total of eight green sturgeon trial days in 2016 (five tanks in trial each day) and 13 green sturgeon trial days in 2017 (six tanks in trial each day, Table 1). Numbers of green sturgeon consumed per trial were used to calculate proportions of green sturgeon consumed in each tank. To summarize the data, the mean proportion of green sturgeon consumed per trial day was calculated across all tanks of predators of the same size and species.

To test the relationships between predator species, predator size and green sturgeon size on green sturgeon mortality, we used generalized linear mixed models (GLMMs) with a binomial distribution built using $R$ software ( $R$ Core Team 2016). These models included a continuous variable for green sturgeon total length and a quadratic term for length to account for non-linear relationships between size and mortality. They also included an interaction between prey size and a categorical predictor of predator species, as we expect a predation size refuge to depend upon predator species. Due to issues of limited sample size, we were unable to use a full model to estimate parameters for all interactive effects of a priori interest, thus we built separate models for each predator size class to reduce the number of parameters in each model. All linear models were built using the package 'Ime4' (Bates, Maechler, Bolker, \& Walker, 2015). Full models were compared with all nested models, and those with the lowest AICc values are reported (Table 2, Figure 1, Table S3). Tank ID was used as a random effect to account for non-independence of experimental tanks across trials, as the same group of predators remained in each tank across trials. Model assumptions of heteroscedasticity and normality of residuals were evaluated graphically.

TABLE 2 Parameter estimates for the generalized linear mixed models selected through AICc comparison

\begin{tabular}{llll}
\hline Small predators & Estimate & Std. Error & $p$-value \\
\hline Intercept & -2.32 & 0.40 & $<.001$ \\
\hline GS size & 4.53 & 2.18 & .037 \\
\hline GS size ${ }^{2}$ & -5.67 & 2.12 & .008 \\
\hline $\begin{array}{l}\text { Predator species (SB vs. } \\
\text { LMB) }\end{array}$ & -1.08 & 0.64 & .095 \\
\hline $\begin{array}{l}\text { GS Size }{ }^{*} \text { Predator species } \\
\text { (SB vs. LMB) }\end{array}$ & -1.82 & 2.41 & .448 \\
\hline $\begin{array}{l}\text { GS Size } \\
\quad \text { (SB vs. LMB } \text { ) }\end{array}$ & -0.86 & 2.61 & .742 \\
\hline $\begin{array}{l}\text { Large predators species } \\
\text { Intercept }\end{array}$ & Estimate & Std. Error & $p$-value \\
\hline GS size & -1.42 & 0.35 & $<.001$ \\
\hline GS size ${ }^{2}$ & 5.26 & 0.54 & $<.001$ \\
\hline
\end{tabular}

Note: Models were built to estimate the effects of green sturgeon (GS) size, predator species ( $\mathrm{SB}=$ striped bass, $\mathrm{LMB}=$ largemouth bass), and their interaction on green sturgeon mortality from 2016 and 2017 experimental trials.

TABLE 1 Predator species morphometrics and experimental design for the 2016 and 2017 experimental seasons

\begin{tabular}{|c|c|c|c|c|c|c|c|}
\hline Predator Species & Predator size & $N$ & $\begin{array}{l}\text { Mean predator } \\
\mathrm{TL} \pm S D(\mathrm{~cm})\end{array}$ & $\begin{array}{l}\text { Sturgeon size } \\
\text { range }(\mathrm{cm})\end{array}$ & $\begin{array}{l}\% \text { of Sturgeon to } \\
\text { predator } T L(\mathrm{~cm})\end{array}$ & Replicate tanks & $\begin{array}{l}N \text { sturgeon } \\
\text { trials }\end{array}$ \\
\hline Largemouth bass & Large & 5 & $46.0 \pm 3.4$ & $7.6-26.5$ & $17 \%-58 \%$ & 1 & 8 \\
\hline \multirow[t]{2}{*}{ Striped bass } & Large & 15 & $47.9 \pm 3.5$ & $3.7-26.7$ & $8 \%-56 \%$ & 3 & 13 \\
\hline & Small & 15 & $40.6 \pm 4.0$ & & $9 \%-66 \%$ & 3 & 12 \\
\hline
\end{tabular}

Note: Experimental tanks contained between 4-5 predators and were fed 6 prey per predator in each trial.

${ }^{a}$ Sturgeon prey values reported are the smallest and largest individuals of the subset measured from the first and last trials of both experimental seasons. The percentages of sturgeon length to predator length are calculated using the mean predator total lengths for each species and size class. 


\section{2 | Behavioral analysis}

Video recordings of trials were used to conduct behavioral analyses of predators in a subset of experiments using BORIS open-source software (Friard \& Gamba, 2016). Five predation trial days for each predator species (out of a total 8 largemouth bass trials and 13 striped bass trials) were chosen to represent the range of juvenile green sturgeon sizes tested in the experiment. For each trial day, behaviors were evaluated for five tanks due to compromised video recordings for one striped bass tank. This resulted in a total of 25 trials analyzed for each predator species. In addition, predator sizes were aggregated for each species for this analysis.
Predatory behavior analysis followed a conceptual model laid out by Lima and Dill (1990, Figure 2). Following an encounter between predator and prey that led to an attack on the prey, the final outcome was described as a nip (green sturgeon bitten by bass followed by prey escape), rejection (green sturgeon is captured by bass followed by prey escape) or consumption of the prey. Of the three predatory behaviors quantified, nips and rejections were classified as predation attempts, while consumptions were successful predation events. These three behaviors were quantified for the first hour of each selected trial. A pilot analysis of experimental observations from all recorded daylight hours showed that the majority of predatory behavior occurred during the first hour following release of prey into the tank.
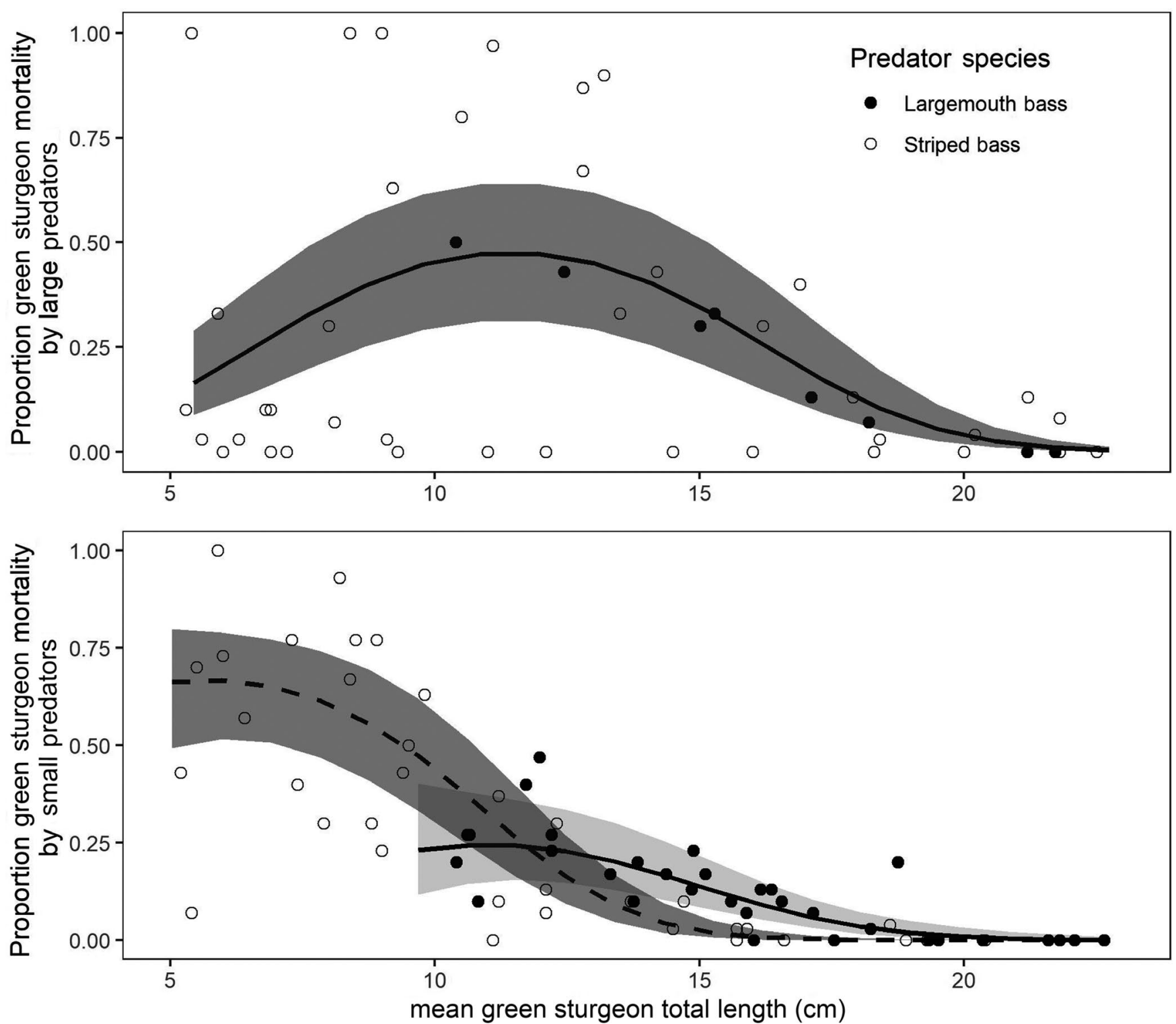

FIGURE 1 Generalized linear mixed model (GLMM) predictions of green sturgeon mortality by largemouth bass (solid line) and striped bass (dashed line) of large and small size classes. Predictor variables in the small predator GLMM were green sturgeon size and its quadratic term, predator species, and their interaction. Predictor variables in the large predator GLMM were green sturgeon size and its quadratic term. Raw data points are plotted, with open circles indicating observed mortality from striped bass predators, and closed circles representing mortality from largemouth bass predators. Shaded areas represent $95 \%$ confidence intervals based on GLMM predictions 
To test the relationships between predator species and green sturgeon size on the frequency of each behavior, generalized linear mixed models with a Poisson distribution were built in R software to predict each behavior type. These models included a continuous variable for green sturgeon total length and a quadratic term for length to account for non-linear relationships between prey size and predator behavior frequencies. They also included an interaction between prey size and a categorical predictor of predator

\section{Encounter}

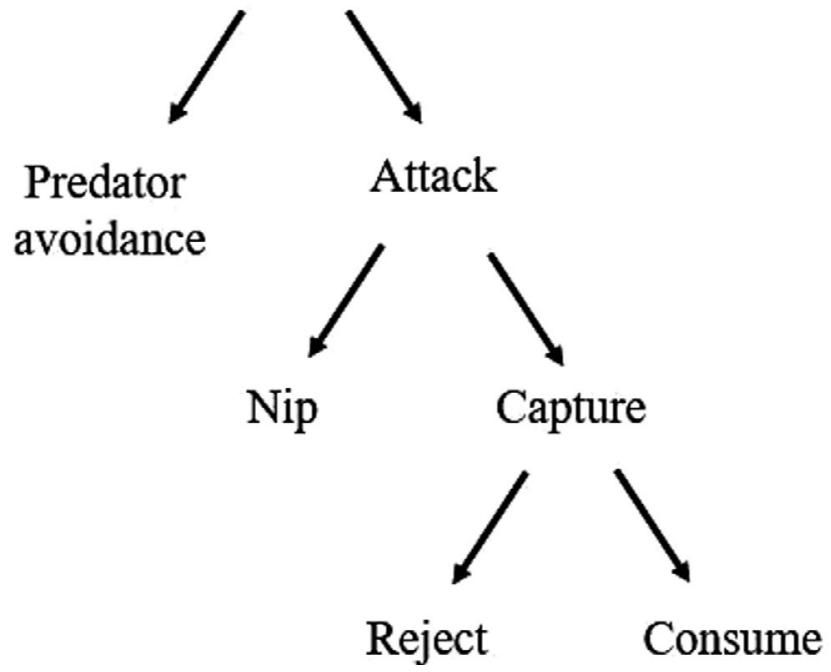

FIGURE 2 Conceptual model modified from Figure 1 of Lima and Dill (1990) used as a framework for behavioral analysis of predator and prey species, as we expect predator species to differ in their behaviors. Full models were compared with all nested models for each behavior, and those models with the lowest AICc values are reported (Table 3, Figure 3, Table S4). Tank ID was used as a random effect to account for the non-independence of experimental tanks across trials. Model assumptions of heteroscedasticity and normality of residuals were evaluated graphically.

\section{RESULTS}

\section{1 | Green sturgeon mortality}

Overall, predation on green sturgeon was consistently lower than that of alternate prey (Figure 4). For largemouth bass, all alternate prey were consumed except for one experiment where the alternate prey (rainbow trout) were large and predators were likely satiated. For striped bass, all alternate prey (fathead minnows) were consumed in each trial.

In addition to the lower predation rates on green sturgeon compared to the alternate prey, peak consumption of green sturgeon occurred at smaller size classes, with a decreasing trend in mortality as sturgeon grew in total length (Figure 4). Peak consumptions by small and large largemouth bass occurred when green sturgeon were $12.1 \mathrm{~cm}$ TL (mean proportion consumed $=0.34$ ) and $10.6 \mathrm{~cm} \mathrm{TL}$ (mean proportion consumed $=0.50$ ), respectively. Peak consumptions by small and large striped bass occurred when green sturgeon were $6.1 \mathrm{~cm} \mathrm{TL}$ (mean proportion consumed $=0.77$ ) and $11.0 \mathrm{~cm}$ TL (mean proportion consumed $=0.61$ ), respectively. Predation rates dropped to nearly zero by $22.0 \mathrm{~cm}$ TL for both size classes of both

TABLE 3 Parameter estimates for the generalized linear mixed models selected through AICc comparison

\begin{tabular}{|c|c|c|c|c|}
\hline Behavior & Variable & Estimate & Std. Error & $p$-value \\
\hline \multirow{3}{*}{ Nips } & GS size & 2.1 & 0.78 & .007 \\
\hline & Predator Species (SB vs. LMB) & -1.18 & 0.17 & $<.001$ \\
\hline & GS size * Predator Species & 4.33 & 1.27 & $<.001$ \\
\hline \multirow[t]{4}{*}{ Rejections } & Intercept & 0.62 & 0.46 & .165 \\
\hline & GS size & 7.13 & 1.47 & $<.001$ \\
\hline & GS size ${ }^{2}$ & -7.90 & 1.59 & $<.001$ \\
\hline & Predator Species (SB vs. LMB) & -1.13 & 0.23 & $<.001$ \\
\hline \multirow{3}{*}{ Consumptions } & Predator Species (SB vs. LMB) & 1.70 & 1.16 & .142 \\
\hline & GS size * Predator Species & -14.90 & 9.06 & .100 \\
\hline & GS size ${ }^{2 *}$ Predator Species & 14.99 & 10.07 & .136 \\
\hline
\end{tabular}

Note: Models were built to estimate the effects of green sturgeon (GS) size, predator species (SB = striped bass, LMB = largemouth bass), and their interaction on the frequency of predatory behaviors from 2016 and 2017 experimental trials. 

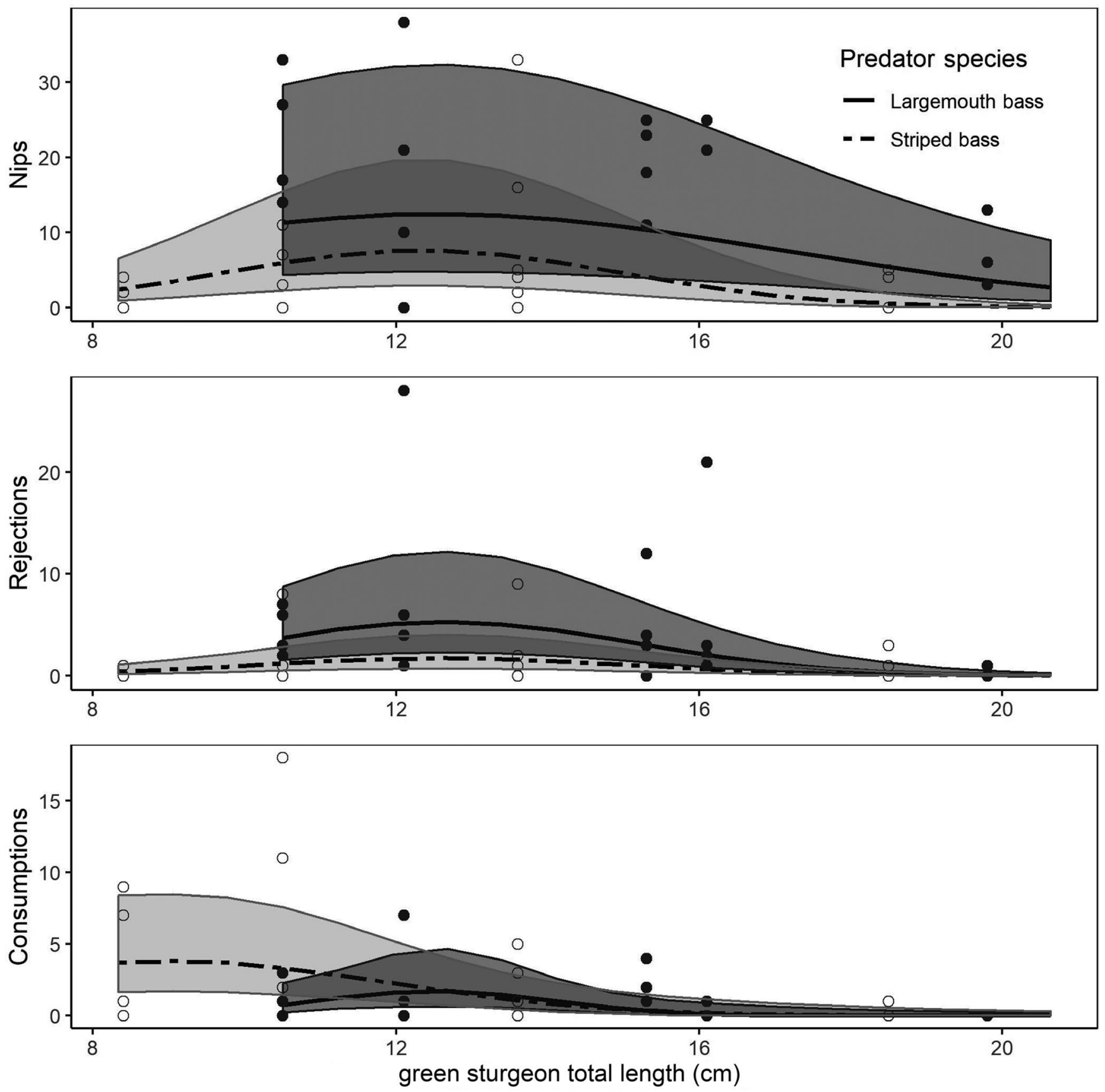

FIGURE 3 Generalized linear mixed model (GLMM) predictions of the occurrences of three predatory behaviors by largemouth bass (solid line) and striped bass (dashed line) of large and small size classes. Behaviors were quantified during the first hour of a subset of experimental trials. Predictor variables in the GLMM were green sturgeon size and its quadratic term, predator species, and their interaction. Raw data points are represented as filled (largemouth bass) and open (striped bass) circles. Shaded areas represent $95 \%$ confidence intervals based on GLMM predictions

predator species. Across all experimental trials where prey were consumed, the ratio of green sturgeon to largemouth bass total length ranged from $31 \%-58 \%$ for small predators, and $23 \%-38 \%$ for large predators. The ratio of green sturgeon to striped bass total length ranged from $13 \%-45 \%$ for small predators, and $11 \%-46 \%$ for large predators. These values were calculated using the mean sturgeon total lengths for the respective trial and the mean total lengths for each predator species and size class. Sturgeon larger than these were provided in later trials, yet were not consumed (Tables S1 and S2).

An evaluation of the predictive power of GLMMs using AICc indicated that predator species alone was not an important predictor of green sturgeon mortality, however for small predators the interaction between predator species and prey size was included in the best model. Additionally, for both GLMMs, green sturgeon size and its quadratic term were included (Table 2). The best explanatory models 


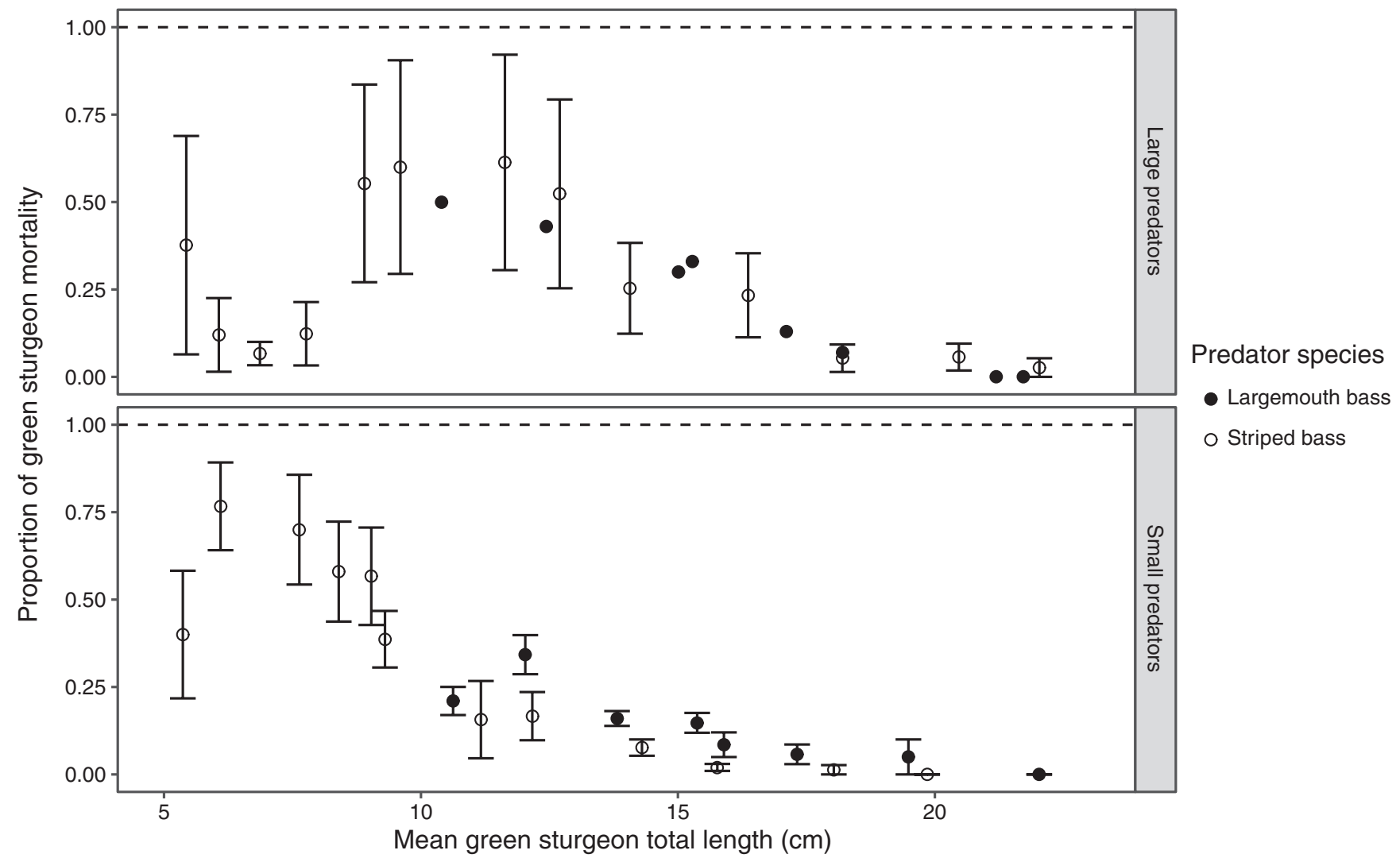

FIGURE 4 Proportion of green sturgeon consumed (mean \pm SE) by largemouth bass (closed circles) and striped bass (open circles) in relation to mean green sturgeon total length $(\mathrm{cm})$ at each trial. The top plot includes large size classes of both predator species, and the bottom plot includes small size classes of both predator species. The dashed horizontal line at 1.0 represents nearly complete predation of alternate prey for both predator species and size classes

identified through AICc selection explained $54.8 \%$ and $24.7 \%$ of the deviance in the data for small and large predators, respectively.

\section{2 | Behavioral analysis}

The frequencies of each predatory behavior differed slightly between the two predator species. The quantified behaviors showed that while striped bass consumed more green sturgeon in the first hour of experiments, largemouth bass attempted predation (both nips without capture and rejections after capture) more often than striped bass (Figure 5). The frequency of predatory behaviors through green sturgeon development changed, with a peak in each behavior followed by a decline as green sturgeon grew in total length (Figure 3). Additionally, predation attempts occurred more frequently than consumptions throughout experimental trials of both predator species. Statistical analysis of each predatory behavior indicated that predator species and green sturgeon size were important in predicting the frequency of predatory behaviors, and that the effect of sturgeon size on frequency of predation attempts differed by predator species (GLMM, Table 3). The best explanatory models identified through AICc selection explained $27.8 \%, 29.1 \%$ and $27.8 \%$ of the deviance in the data for nips, rejections and consumptions, respectively.

\section{5 | DISCUSSION}

Predation on juvenile green sturgeon in our study was relatively low when compared to alternate prey, and decreased as sturgeon grew. Lower predation rates on sturgeon than on alternative prey is consistent with other studies using juvenile sturgeon species and predatory fishes such as smallmouth bass (M. dolomieu), northern pikeminnow, and walleye (French et al., 2010; Gadomski \& Parsley, 2005). However, these studies also showed that predation by littoral and pelagic predators occurred at lower rates than predation by more benthically oriented predators such as channel catfish, prickly sculpin and flathead catfish, which were found to feed on larval white sturgeon and pallid sturgeon at higher rates than littoral and pelagic predators in laboratory experiments (French, Graeb, Chipps, \& Klumb, 2014; Gadomski \& Parsley, 2005). Juvenile green sturgeon are largely benthic, suggesting that encounters with pelagic and limnetic predators such as largemouth bass and striped bass may be less frequent than encounters with benthic predators such as catfish and sculpin species.

Consumption of juvenile green sturgeon decreased as the sturgeon grew in size, thus the period of vulnerability to predation is size-dependent in the freshwater and estuarine environments, likely due to gape-limited predators in these habitats. The maximum prey total length ingested by these predators ranged from $38 \%-58 \%$ of the 


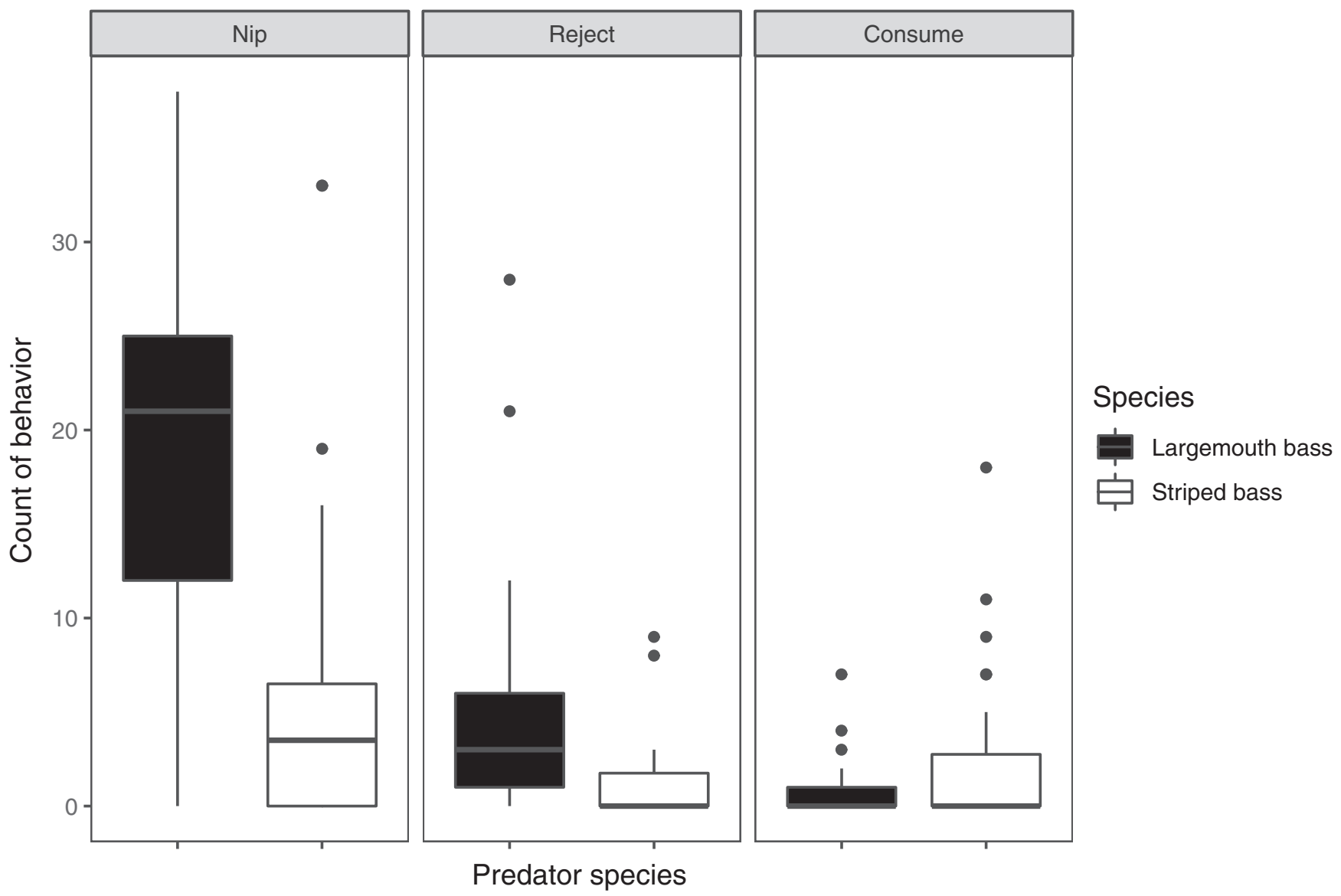

FIGURE 5 Distribution of total counts of each behavior (nip, reject, consume) for the first hour of selected largemouth bass (black) and striped bass (white) trials $(n=25)$. Boxes represent the inter-quartile range (IQR), whiskers extend 1.5 times IQR and horizontal lines show overall medians. Outliers are presented as black dots

total length of the predator, which is consistent with data collected on various freshwater piscivorous fishes including largemouth bass (Gaeta et al. 2018). The dependence of predation risk on sturgeon size indicates that growth rates of larval and juvenile sturgeon is an important determinate of the duration of vulnerability to gape-limited predators (Houde, 1987). Laboratory experiments assessing the effect of temperature, food availability, and the interaction between the two have shown that growth rates are very sensitive to these factors, and thus variation in rearing habitat quality can induce large variation in growth rates and overall size amongst juvenile green sturgeon of the same age (Poletto et al., 2018). Taken together, larval and juvenile rearing conditions may strongly influence the window of vulnerability to predation as green sturgeon out-migrate through the Sacramento San Joaquin watershed.

We documented higher rates of predation attempts than consumptions. Although predation attempts (nips and rejections) may not directly cause green sturgeon mortality, they may cause non-consumptive effects such as injury, preventing proper movement and growth. In addition, predation attempts may cause green sturgeon to reduce overall activity in order to avoid predators, indirectly affecting growth rates, foraging behavior, metabolic rates, and migratory behavior (Preisser, Bolnick, \& Bernard, 2005). Experiments exposing juvenile shovelnose sturgeon (Scaphirhynchus platorynchus) to channel catfish predators (Hintz, Grimes, \& Garvey, 2013), and others exposing white sturgeon to largemouth bass (Steel, Hansen, Cocherell, \& Fangue, 2019), showed that sturgeon which were chased or bitten by a predator exhibited a greater predator avoidance response. These predator avoidance responses included both spatial avoidance and reduced activity levels, each of which has the potential to reduce foraging opportunities or other fitness-enhancing behaviors. Predation attempts were a common occurrence in our trials, particularly by largemouth bass predators, suggesting even non-consumptive interactions may have negative effects on juvenile green sturgeon.

Behaviorally, we observed both predator species reject sturgeon after capture. For experiments with largemouth bass, there were more rejections after capture than consumptions. Predation studies on other juvenile sturgeon species found similar trends using different predator species (French et al., 2014; Hintz et al., 2013). The sharp dorsal and lateral scutes of sturgeon may act as a deterrent to predation, as documented in other fish species that possess sharp defensive structures (Abrahams, 1995; Gross, 1978). The armoring of juvenile sturgeon may increase handling time for a predator and may cause injury to the predator, rendering them a suboptimal prey choice (Lima, 1998). Scutes may also decrease the probability of death given an encounter by increasing 
the likelihood of a predator discarding the sturgeon, or increasing the ability to escape (French et al., 2014; Gross, 1978).

Conditions used in this experiment do not replicate natural environmental conditions, however they were chosen to optimize predation opportunity. There was no cover or structure for juvenile green sturgeon to use as refuge, yet previous work has shown that refuge use by prey increases in the presence of predators (Wahl et al., 2012). In addition, rearing conditions of green sturgeon were optimal, and there was no prior exposure to predatory fishes before each trial, preventing any learned anti-predator behavior, which has been documented to increase survival in other fish species (Wahl et al., 2012). In natural environments, habitat heterogeneity, refugia structures, turbidity, deeper water and additional prey species could all affect encounter rates between juvenile green sturgeon and these two pelagic/limnetic predator species (Savino \& Stein, 1982). In particular, the presence of alternate prey species is likely to lower the predation pressures on juvenile green sturgeon, as has been shown in previous studies (Forney, 1974; Gotceitas \& Brown, 1993; Pepin \& Shears, 1995). However, the consistently low predation rates on juvenile green sturgeon under these conditions further supports the idea that most wild green sturgeon juvenile mortality is likely not due to these two abundant predator species.

In contrast to the exposure of green sturgeon to predator species, the predators used during experiments were not naïve to sturgeon prey. Repeated exposure to sturgeon may have resulted in learned predator behavior and altered the results of subsequent trials. Flathead catfish predators exposed to juvenile pallid sturgeon also exhibited fewer predation attempts and consumptions in trials where predators were used repeatedly (French et al., 2014), suggesting the decreasing consumptions of sturgeon could be attributed to predator learning. In previous experiments where juvenile channel catfish, another fish with defensive structures, were exposed to predation by largemouth bass, injuries to predators by catfish spines were frequently observed. In trials following injury by catfish spines, largemouth bass exhibited caution to catfish prey (Bosher, Newton, \& Fine, 2006). Although injury by consuming juvenile green sturgeon may not be quite as severe, future work should expose naïve predators to various sizes of sturgeon prey to rule out the effect of predator learning in our study.

Overall, motivation to feed on juvenile green sturgeon in the current experiments was low, as shown through the stark differences in consumptions between alternate prey and sturgeon prey as well as analysis of predation behaviors. Although largemouth bass and striped bass are thought to represent dominant predators in the San Francisco Bay-Delta system, further experiments should include predators which spend more time in similar levels of the water column with juvenile green sturgeon, such as channel catfish and white catfish (Ameiurus catus). Results show that the window in which juvenile green sturgeon are vulnerable to predation by the two generalist predators evaluated here is narrow and dependent upon the relationship between predator and prey size, with predation becoming negligible once sturgeon reached a length threshold of roughly $20-22 \mathrm{~cm}$ total length, or between $38 \%$ and $58 \%$ of predator total length. More studies are necessary to understand the spatial and temporal distributions of developing green sturgeon in the Sacramento-San Joaquin Delta to know the extent of overlap between these particular predatory species and juvenile green sturgeon during their vulnerable size window.

\section{ACKNOWLEDGEMENTS}

The authors would like to thank the California Department of Water Resources for predator collection and funding and the students and staff of the Fangue Fish Ecophysiology laboratory for assistance with fish husbandry and maintenance. We thank Joel van Eenennaam for his expertise in spawning the adult green sturgeon, and the Yurok Tribe of Northern California for generously donating the green sturgeon broodstock. We thank the U.S. Bureau of Reclamation for collection and donation of striped bass predators and the UC Davis Agricultural Experiment Station (Award number 2098-H) for additional support. Lastly, we thank the editor and anonymous referees for their valuable insight during review of the manuscript.

\section{DATA AVAILABILITY STATEMENT}

The datasets analyzed during this study will be made available upon acceptance in the Environmental Data Initiative repository, https:// portal.edirepository.org/nis/home.jsp, with a unique doi.

\section{ORCID}

Sarah E. Baird iD https://orcid.org/0000-0003-0144-6998

Anna E. Steel iD https://orcid.org/0000-0002-1420-1853

\section{REFERENCES}

IUCN 2019. IUCN Red List of Threatened Species. Version 2019-2 <www. iucnredlist.org>.

Abrahams, M. V. (1995). The interaction between antipredator behaviour and antipredator morphology: Experiments with fathead minnows and brook sticklebacks. Canadian Journal of Zoology, 73(12), 22092215. https://doi.org/10.1139/z95-261

Adams, P. B., Grimes, C., Heightower, J. E., Lindley, S. T., Moser, M. L., \& Parsley, M. J. (2007). Population status of North American green sturgeon, Acipenser medirostris. Environmental Biology of Fishes, 79, 339-356.

Allen, P. J., \& Cech, J. J. Jr (2007). Age/size effects on juvenile green sturgeon, Acipenser medirostris, oxygen consumption, growth, and osmoregulation in saline environments. Environmental Biology of Fishes, 79, 211-229.

Bates, D., Maechler, M., Bolker, B., \& Walker, S. (2015). Fitting linear mixed-effects models using Ime4. Journal of Statistical Software, 67, 1-48. https://doi.org/10.18637/jss.v067.i01

Birstein, V. J. (1993). Sturgeons and paddlefishes: Threatened fishes in need of conservation. Conservation Biology, 7(4), 773-787.

Bosher, B. T., Newton, S. H., \& Fine, M. L. (2006). The spines of the channel catfish, Ictalurus punctatus, as an antipredator adaptation: An experimental study. Ethology, 112, 188-195.

California Department of Water Resources, Bay-Delta Office. (2017). Clifton Court Forebay Predator Reduction Electrofishing Study Annual Report. https://water.ca.gov/-/media/DWR-Website/Web-Pages/ Programs/Bay-Delta/Bay-Delta-Environmental-Compliance/CliftonCourt-Forebay-Electrofishing-Study/PRES_2017_Report_FINAL.pdf.

R Core Team. (2016). R: A language and environment for statistical computing. Vienna, Austria: R Foundation for Statistical Computing. URL: https://www.R-project.org/.

Coutant, C. C. (2004). A riparian habitat hypothesis for successful reproduction of white sturgeon. Reviews in Fisheries Science, 12(1), 23-73. https://doi.org/10.1080/10641260490273023. 
Davis, J. P., Schultz, E. T., \& Vokoun, J. C. (2012). Striped Bass consumption of Blueback Herring during vernal riverine migrations: Does relaxing harvest restrictions on a predator help conserve a prey species of concern? Marine and Coastal Fisheries: Dynamics, Management and Ecosystem Science, 4(1), 239-251. https://doi.org/10.1080/19425120.2012.675972

Forney, J. L. (1974). Interactions between yellow perch abundance, walleye predation, and survival of alternate prey on Oneida Lake, New York. Transactions of the American Fisheries Society, 103, 15-24.

French, W. E., Graeb, B. D. S., Chipps, S. R., Bertrand, K. N., Selch, T. M., \& Klumb, R. A. (2010). Vulnerability of age-0 pallid sturgeon Scaphirhynchus albus to fish predation. Journal of Applied Ichthyology, 26(1), 6-10.

French, W. E., Graeb, B. D. S., Chipps, S. R., \& Klumb, R. A. (2014). Vulnerability of age- 0 pallid sturgeon Scaphirhynchus albus to predation; effects of predator type, turbidity, body size, and prey density. Environmental Biology of Fishes, 97(6), 635-646.

Friard, O., \& Gamba, M. (2016). BORIS: A free, versatile open-source event-logging software for video/audio coding and live observations. Methods in Ecology and Evolution, 7, 1325-1330. https://doi. org/10.1111/2041-210X.12584

Gadomski, D. M., \& Parsley, M. J. (2005). Laboratory studies on the vulnerability of young white sturgeon to predation. North American Journal of Fisheries Management, 25(2), 667-674. https://doi. org/10.1577/M03-220.1

Gotceitas, V., \& Brown, J. A. (1993). Risk of predation to fish larvae in the presence of alternative prey: The effects of prey size and number. Marine Ecology Progress Series, 98, 215-222.

Gross, H. P. (1978). Natural selection by predators on the defensive apparatus of the three-spined stickleback, Gasterosteus aculeatus L. Canadian Journal of Zoology, 56, 398-413. https://doi.org/10.1139/z78-058

Grossman, G. D. (2016). Predation on fishes in the Sacramento-san Joaquin delta: current knowledge and future directions. San Francisco Estuary and Watershed Science, 14(2), https://escholarship.org/uc/ item/9rw9b5tj. https://doi.org/10.15447/sfews.2016v14iss2art8

Hintz, W. D., Grimes, G. T., \& Garvey, J. E. (2013). Shovelnose sturgeon exhibit predator avoidance behaviour in the presence of a hungry predator. Journal of Applied Ichthyology, 29, 2-5.

Houde, E. D. (1987). Fish early life dynamics and the recruitment variability. Pages 17-29 in R. D. Hoyt editor. 10th annual larval fish conference. American Fisheries Society, Symposium 2, Bethesda, Maryland.

Israel, J. A., Cordes, J. F., Blumberg, M. A., \& May, B. (2004). Geographic patterns of genetic differentiation among collections of green sturgeon. North American Journal of Fisheries Management, 24, 922-931.

Kano, R. M. (1990). Occurrence and abundance of predator fish in Clifton Court Forebay, California. Technical Report 24. Interagency Ecological Program.

Kovalenko, K. E., Dibble, E. D., Agostinho, A. A., \& Pelicice, F. M. (2010). Recognition of non-native peacock bass, Cichlea kelberi by native prey: Testing the naiveté hypothesis. Biological Invasions, 12, 3071-3080.

Lima, S. L. (1998). Nonlethal effects in ecology of predator-prey interactions. BioScience, 48(1), 25-34.

Lima, S. L., \& Dill, L. M. (1990). Behavioral decisions made under the risk of predation: A review and prospectus. Canadian Journal of Zoology, 68, 619-640.

National Marine Fisheries Service (2006). Endangered and threatened wildlife and plants: Threatened status for southern Distinct Population Segment of North American green sturgeon. Federal Register, 71, 67.

National Marine Fisheries Service (2018). Recovery plan for the southern distinct population segment of North American green sturgeon (Acipenser medirostris). Sacramento, CA: National Marine Fisheries Service.

Parsley, M. J., Anders, P. J., Miller, A. I., Beckman, L. G., \& McCabe, G. T. Jr (2002). Recovery of white sturgeon populations through natural production: Understanding the influence of abiotic and biotic factors on spawning and subsequent recruitment. American Fisheries Society Symposium, 2002(28), 55-66.

Pepin, P., \& Shears, T. H. (1995). Influence of body size and alternate prey abundance on the risk of predation to fish larvae. Marine Ecology Progress Series, 128, 279-285.

Persson, L., Andersson, J., Wahlstrom, E., \& Eklov, P. (1996). Size dependent predator-prey interactions in whole lake systems: Predator gape limitation and prey growth rate and mortality. Ecology, 77, 900-911.

Poletto, J. B., Martin, B., Danner, E., Baird, S. E., Cocherell, D. E., Hamda, N., ... Fangue, N. A. (2018). Assessment of multiple stressors on the growth of larval green sturgeon Acipenser medirostris: Implications for recruitment of early life-history stages. Journal of Fish Biology, 93, 952-960. https://doi.org/10.1111/jfb.13805

Preisser, E. L., Bolnick, D. I., \& Bernard, M. F. (2005). Scared to death? The effects of intimidation and consumption in predator-prey interactions. Ecology, 86, 501-509.

Savino, J. F., \& Stein, R. A. (1982). Predator-prey interaction between largemouth bass and bluegills as influenced by simulated, submersed vegetation. Transactions of the American Fisheries Society, 111(3), 255-266.

Schael, D. M., Rudstam, L. G., \& Post, J. R. (1991). Gape limitation and prey selection in larval yellow perch (Perca flavescens), freshwater drum (Aplodinotus grunniens), and black crappie (Pomoxis nigromaculatus). Canadian Journal of Fisheries and Aquatic Sciences, 48(10), 1919-1925.

Sih, A., Bolnick, D. I., Luttbeg, B., Orrock, J. L., Peacor, S. D., Pintor, L. M., ... Vonesh, J. R. (2010). Predator-prey naivete, antipredator behavior, and the ecology of predator invasions. Oikos, 119, 610-621.

Steel, A. E., Hansen, M. J., Cocherell, D. E., \& Fangue, N. A. (2019). Behavioral responses of juvenile white sturgeon (Acipenser transmontanus) to manipulation of nutritional state and predation risk. Environmental Biology of Fishes, 102(5), 817-827.

Van Eenennaam, J. P., Linares-Casenave, J., \& Doroshov, S. I. (2012). Tank spawning of first generation domestic green sturgeon. Journal of Applied Ichthyology, 28(4), 505-511.

Verhille, C. E., Lee, S., Todgham, A. E., Cocherell, D. E., Hung, S. S. O., \& Fangue, N. A. (2016). Effects of nutritional deprivation on juvenile green sturgeon growth and thermal tolerance. Environmental Biology of Fishes, 99, 145-159. https://doi.org/10.1007/s10641-015-0463-8

Wahl, D. H., Einfalt, L. M., \& Wojcieszak, D. B. (2012). Effect of experience with predators on the behavior and survival of muskellunge and tiger muskellunge. Transactions of the American Fisheries Society, 141, 139-146. https://doi.org/10.1080/00028487.2011.652011

Zheng, K. K., Deng, D. F., De Riu, N., Moniello, G., \& Hung, S. S. O. (2015). The effect of feeding on the growth performance of green sturgeon. Aquaculture Nutrition, 21(4), 489-495. https://doi.org/10.1111/ anu.12179

\section{SUPPORTING INFORMATION}

Additional supporting information may be found online in the Supporting Information section.

How to cite this article: Baird SE, Steel AE, Cocherell DE, Poletto JB, Follenfant R, Fangue NA. Experimental assessment of predation risk for juvenile green sturgeon, Acipenser medirostris, by two predatory fishes. J Appl Ichthyol. 2020;36:14-24. https://doi.org/10.1111/jai.13990 